\title{
Further studies on the metabolism by rats of intravenously administered aqueous dispersions of carotenoid pigments
}

\author{
By W. A. McGILLIVRAY, S. Y. THOMPSON* \\ AND N. A. WORKER \\ Biochemistry Department, Massey Agricultural College (University of \\ New Zealand), Palmerston North, New Zealand \\ (Received 23 November 1955)
}

In a previous communication (Kon, McGillivray \& Thompson, 1955) we reported some of our findings on the metabolism of vitamin $\mathrm{A}$ and carotene administered intravenously to rats and calves partially deficient in vitamin A, and to rabbits with normal vitamin A reserves. These findings, in agreement with those of Bieri \& Pollard (1954) and Bieri (1955), showed that carotene, when administered intravenously as an aqueous dispersion, could be converted into vitamin $A$ by rats and rabbits at a site other than the intestine. The vitamin first appeared in the blood as the alcohol, whereas after oral administration the initial increase is mainly as ester (Thompson, Ganguly \& Kon, I949). With calves, however, no evidence of conversion of the intravenously administered carotene was found, which indicates a possible species difference (cf. Church, MacVicar, Bieri, Baker \& Pope, 1954). One problem encountered in this work was the high toxicity for calves of the injected Tween dispersions and hence the relatively lower doses of carotene that could be used. It seemed important, therefore, to investigate further the conversion in rats given similar carotene levels. Studies were also made of the conversion in rats not deficient in vitamin A. In vitamin A-deficient rats the metabolism of other carotenoid pigments similarly administered was studied, together with the effects of hypo- and hyperthyroidism and of complete hepatectomy on the conversion of carotene.

\section{EXPERIMENTAL}

The methods and materials used were essentially as described in the earlier paper (Kon et al. 1955) with the additions or modifications listed below.

\section{Preparation of carotenoid pigments}

Carotene. Unless otherwise stated, crystalline carotene (L. Light and Co. Ltd) containing about $88 \% \beta$-carotene was used. For comparing the activity of $\alpha$ - and $\beta$-carotene this material was separated by chromatography on magnesium oxide into $\alpha$ and $\beta$ fractions.

Lycopene. Lycopene was extracted from tomatoes by means of acetone in the cold and purified by chromatography on alumina.

* On leave from the National Institute for Research in Dairying, University of Reading, England. 
Xanthophylls. Fresh grass was extracted with acetone in the cold, the extract was saponified and xanthophylls were separated from carotene by chromatography on alumina. The crude mixture of xanthophylls was used without further purification.

Zeaxanthin and cryptoxanthin. These pigments were extracted from the calyx of Physalis franchetii essentially as described by Braude, Foot, Henry, Kon, Thompson $\&$ Mead (194I) and separated by chromatography on magnesium oxide.

Retinene. Retinene was prepared from vitamin A alcohol by the method of Ball, Goodwin \& Morton (1948).

Identification. The identity of all pigments was further confirmed from their absorption spectra.

Aqueous dispersions of pigments. Aqueous dispersions of the various pigments were prepared with a $20 \%(\mathrm{v} / \mathrm{v})$ solution in water of Tween 40 (polyoxyethylenesorbitan monopalmitate, Atlas Powder Co., Wilmington, Delaware), as described by Bieri \& Pollard (1954) and as used in our previous investigations (Kon et al. 1955).

\section{Preparation and dosing of rats}

The rats used were albino of the Wistar strain bred from stock introduced into New Zealand and maintained as an inbred colony since 1932 by Dr I. J. Cunningham, Superintendent of the Wallaceville Research Station, Wellington. The stock-colony rats received a basal diet prepared for us in pellet form by W. and R. Fletcher (N.Z.) Ltd, Wellington, of the approximate composition: ground wheat 42 , ground barley I0.5, ground oats 4 , dried skim milk 34 , wheat germ $8, \mathrm{CaCO}_{3} \mathrm{I}, \mathrm{NaCl} 0.5 \%$. The diet was supplemented once weekly with raw liver and a proprietary emulsion containing both vitamins $A$ and $D$.

For vitamin A work pregnant does were given the basal diet supplemented only with vitamin $\mathrm{D}$ for a week before parturition and throughout lactation. The young continued to receive the diet and were generally used when 200-300 $\mathrm{g}$ in weight, by which time no vitamin A could be detected in the liver.

For work on the effect of the thyroid, rats were rendered hypothyroid by complete removal of thyroids and parathyroids or by treatment with thiouracil, or rendered hyperthyroid by injections with the sodium salt of L-thyroxine (British Drug Houses Ltd). All animals not thyroidectomized, including controls, were subjected to a sham operation. As an index of the effect of these treatments the oxygen consumption of the rats was measured by a modification of Morrison's ( 1947 ) method. The determinations were made on groups of up to three rats in three consecutive $\frac{1}{4} \mathrm{~h}$ periods.

In the experiments in which hepatectomy was performed, owing to the difficulties of either cannulation or the establishment of collateral circulation in the rat, a simple, acute technique was adopted. After the injection subcutaneously of a glucose solution the animals, maintained under diethyl-ether anaesthesia, were opened by mid-line ventral incision extended to the left laterally as near as possible to the ribs. The aorta was ligated as near as possible to the pleural cavity; the portal vein was ligated as near as possible to the liver and the vena cava below and above the liver. The liver, including the section of the vena cava embedded in it, was then removed. The operated animals 
received the dose of carotene in Tween by the jugular vein and were killed up to $\frac{1}{2} \mathrm{~h}$ later.

In all other animals the injection was made into the vena cava exposed by mid-line ventral incision.

\section{RESULTS}

\section{Blood levels of vitamin $A$}

We have noticed marked differences in the content of vitamin $A$ in the blood in different groups of our rats. Rats from normal mothers placed on the deficient diet and depleted of their liver reserves had around $20 \mu \mathrm{g} / \mathrm{r} 00 \mathrm{ml}$. plasma (Table I, Exp. r). Rats similarly depleted, but from partially depleted mothers, had only about ro $\mu \mathrm{g} / \mathrm{r} 00 \mathrm{ml}$. (Table I, Exp. 2). Subsequently, rats, whether depleted or normal with high liver reserves, had only ro $\mu \mathrm{g} / \mathrm{r} 00 \mathrm{ml}$. (see p. I30). We have no explanation to offer at present for this low content in normally fed rats.

\section{Conversion of carotene at low dose levels}

The results presented in Table I (Exp. I) show that the injection of a Tween dispersion containing $35 \mu \mathrm{g}$ carotene, somewhat less on a body-weight basis than previously given to calves by Kon $e$ al. (1955), produced after $2 \mathrm{~h}$ significant increases in both blood and liver vitamin $A$, the increase in the latter being similar to that obtained with $250 \mu \mathrm{g}$ carotene. Another experiment (Table 1, Exp. 2), in which younger rats, more deficient in vitamin $\mathrm{A}$, were injected with a Tween dispersion containing only $25 \mu \mathrm{g}$ carotene, gave similar results. In an experiment not reported in the table, $\mathrm{I} \cdot 2 \mathrm{mg}$ carotene were injected in $\mathrm{I} \cdot 2 \mathrm{ml} .20 \%$ Tween into each of three vitamin A-deficient rats of mean weight $235 \mathrm{~g}$. At slaughter $24 \mathrm{~h}$ later the plasma contained $29 \mu \mathrm{g}$ vitamin A and $65 \mu \mathrm{g}$ carotene/100 $\mathrm{ml}$., and each liver contained on the average $9.3 \mu \mathrm{g}$ vitamin $\mathrm{A}$ alcohol, $26 \mu \mathrm{g}$ vitamin $\mathrm{A}$ ester and $355 \mu \mathrm{g}$ carotene. The controls showed vitamin A levels much the same as those quoted in Table 2, in which are also given results obtained $24 \mathrm{~h}$ after the injection of $300 \mathrm{mg} \beta$-carotene. It is clear that the fourfold increase in dose level resulted in no change in blood vitamin $A$ and only a $50 \%$ increase in liver vitamin A. Carotene levels in blood and livers were, however, considerably higher, the livers showing a tenfold increase.

\section{Effect of the vitamin $A$ status of the animal on the conversion of injected carotene}

For this experiment (Table I, Exp. 3) rats from the same group as those used in Exp. I were given orally sufficient vitamin A to build up high liver reserves before injection of carotene dispersions. In this group of animals, the blood vitamin A levels after injection of $250 \mu \mathrm{g}$ carotene increased by only about $50 \%$, which confirms our previous observations of a $20 \%$ increase in non-deficient stock-colony rats. In these animals with high vitamin $A$ reserves no conversion into vitamin A could be detected when only $35 \mu \mathrm{g}$ carotene were injected. As the liver reserves were high, it is obvious that any increase in vitamin $A$ due to the injected carotene would have been masked by the normal variations in these reserves, and only mean values are given in order to indicate vitamin A status before the carotene injections. 


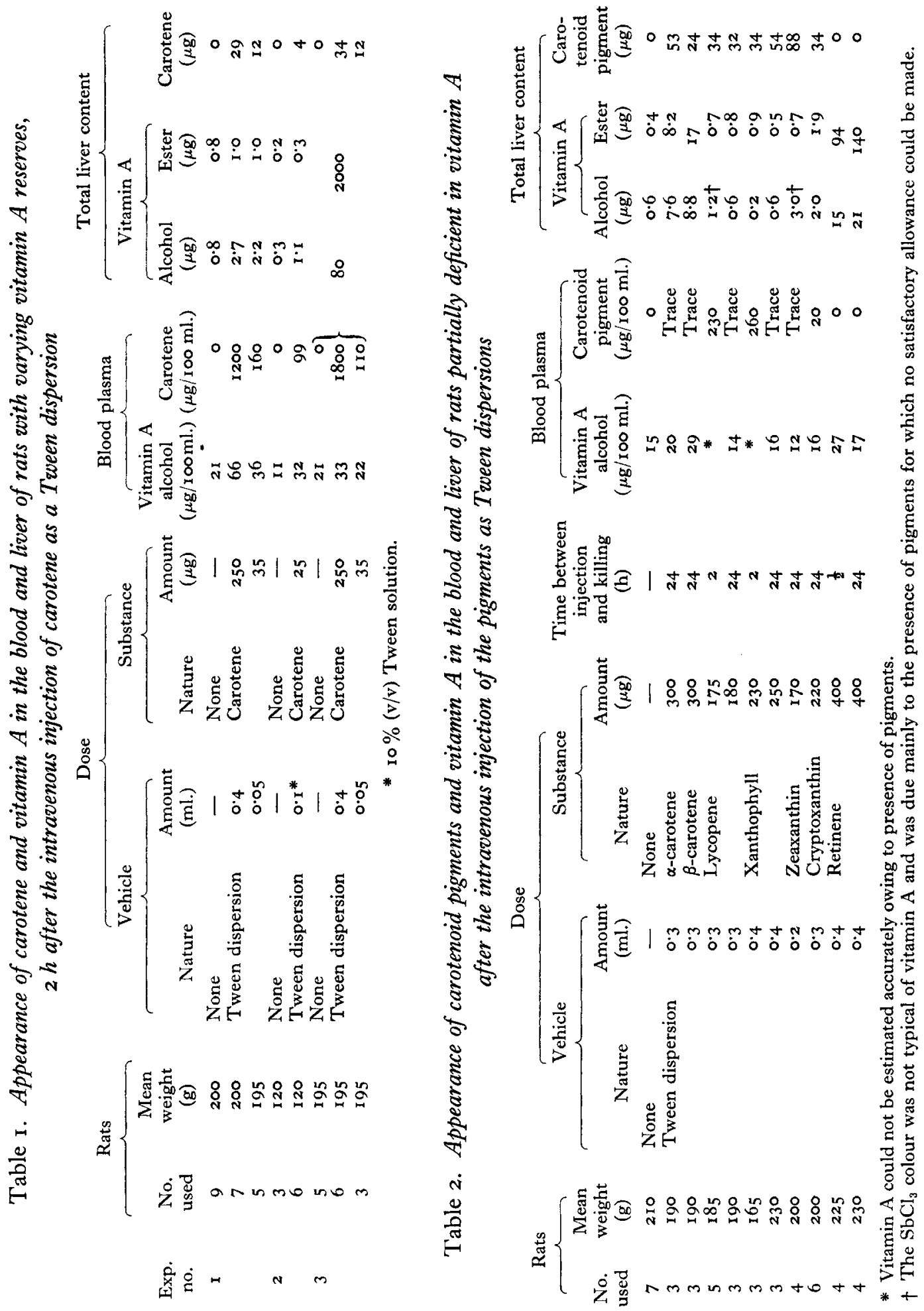




\section{Conversion of carotenoids other than $\beta$-carotene}

Table 2 shows the result of injecting dispersions of various carotenoid pigments into rats partially deficient in vitamin $\mathrm{A}$. Of the pigments investigated, lycopene, xanthophyll and zeaxanthin showed no activity, although some blood and liver samples, particularly at $2 \mathrm{~h}$ after dosing, presented difficulties in interpretation of the $\mathrm{SbCl}_{3}$ reaction owing to the presence of carotenoids, or their decomposition products, that could not be separated entirely from the vitamin $A$ alcohol or ester. $\beta$-carotene was better utilized than $\alpha$-carotene, as judged both by blood vitamin $A$ alcohol and by total liver storage. Cryptoxanthin presents an anomaly, since there was little evidence of conversion into vitamin A after injection, although the same sample when given orally showed the expected activity, $\mathrm{I} \cdot 2 \mathrm{mg}$ giving rise in a deficient rat to $33 \mu \mathrm{g}$ in the liver. Dispersions of retinene were well and rapidly utilized, as $\frac{1}{2} \mathrm{~h}$ after the injection, the shortest time-interval studied, vitamin A mainly as the ester appeared in the liver and no retinene could be detected in either blood or liver.

\section{Effect of thyroid activity on conversion}

From Table 3 it is apparent that wide differences in thyroid activity, as indicated by oxygen-consumption figures, have little influence on the conversion into vitamin $\mathrm{A}$ of intravenously administered carotene. Groups of control, thyroidectomized or hyperthyroid rats showed similar blood levels and liver storage of vitamin A $24 \mathrm{~h}$ after injection. On the other hand, animals rendered hypothyroid by treatment with thiouracil showed somewhat higher liver storage after injection of carotene.

\section{Conversion in hepatectomized animals}

With hepatectomized rats clear evidence of conversion of intravenously administered carotene in Tween was obtained, as indicated by an increase in blood vitamin A alcohol over hepatectomized controls. The mean findings for groups of three vitamin Adeficient rats after injection of $400 \mu \mathrm{g}$ carotene in Tween were as follows:

$\begin{array}{cccc}\text { Group } & \begin{array}{c}\text { Time between } \\ \text { injection and } \\ \text { killing }\end{array} & \begin{array}{c}\text { Vitamin A } \\ \text { alcohol } \\ (\mu \mathrm{g} / \mathrm{ro0} \mathrm{ml} . \\ \text { plasma })\end{array} & \begin{array}{c}\text { Carotene } \\ (\mu \mathrm{g} / \mathrm{I} 00 \mathrm{ml} \\ \text { plasma })\end{array} \\ \text { Control } & - & 10 & 0 \\ \text { I } & - & 57 & 6500 \\ 2 & \frac{1}{12} & 5 \mathrm{I} & 4400 \\ 3 & \frac{1}{2} & 49 & 3300\end{array}$

Similar results were obtained with a group of three rats not deficient in vitamin $A$, the plasma vitamin A alcohol levels having increased after $\frac{1}{4} \mathrm{~h}$ from 10 to $30 \mu \mathrm{g} / \mathrm{I} 00 \mathrm{ml}$. This is clear evidence for the extrahepatic conversion into vitamin A of intravenously administered carotene. In all the experiments reported here blood vitamin A ester values were not recorded, since, as we found in our previous work (Kon et al. 1955), the change in level was of little or no significance.

The results cannot be compared with those in Table $\mathbf{r}$, for the concentration of carotene in the blood of the hepatectomized rats was higher, because the bulk of the dose was restricted by the ligatures to the anterior part of the body. 
Vol. Io

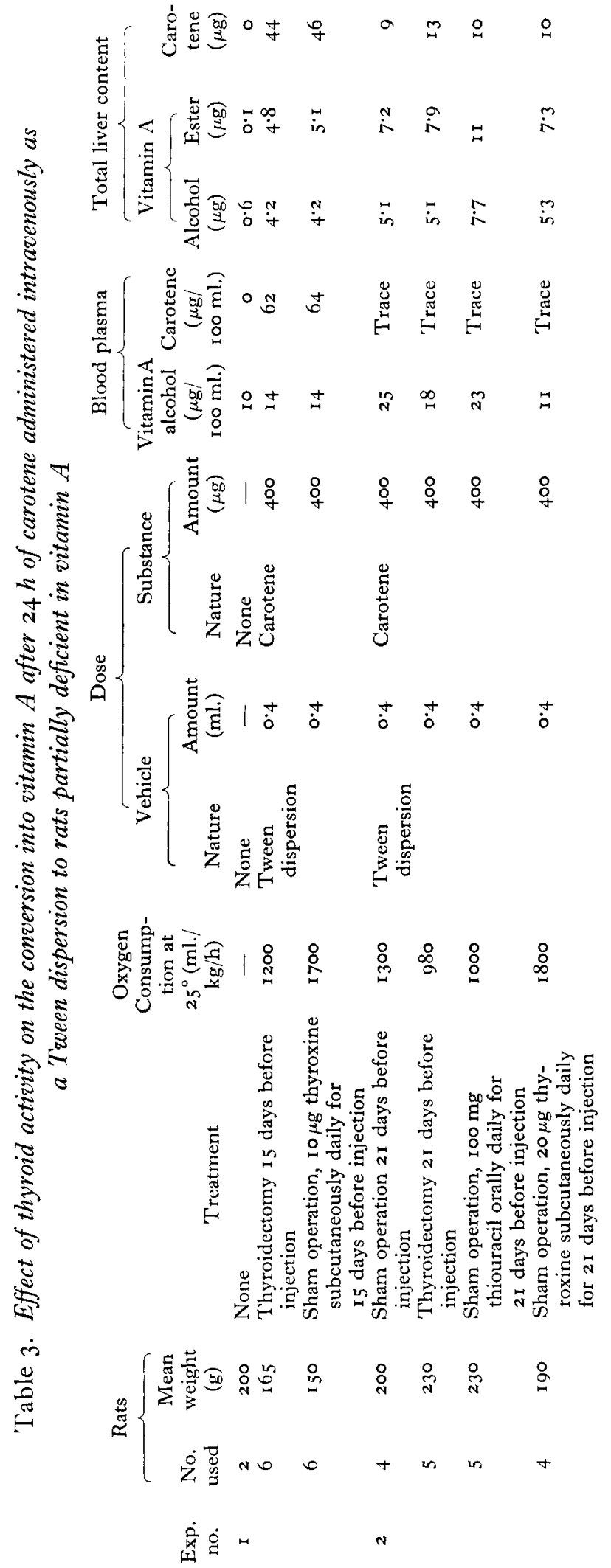


DISCUSSION

From the results presented in Table $\mathbf{I}$ it is clear that, in a species capable of converting intravenously administered carotene dispersions into vitamin $\mathrm{A}$, conversion can be readily detected even when only very small amounts of carotene are administered. Thus, had the calves in our previous study (Kon et al. 1955) been capable of converting the carotene dispersions into vitamin $A$ in a manner similar to that of rats and rabbits, marked increases in blood and liver vitamin $A$ would have resulted with the quantities of carotene administered. A clear species difference in the metabolism of carotene seems, therefore, established (cf. Church et al. 1954).

In the experiments with non-deficient rats the increases of almost $50 \%$ in blood vitamin A levels after injection of $250 \mu \mathrm{g}$ carotene confirm our previous observations with stock-colony rats. Although the increases were less on a percentage basis than in partially deficient rats, it is clear that the conversion of intravenously administered carotene also occurs in normal rats and is not merely an alternative mechanism in animals with low vitamin $A$ reserves.

From the results presented in Table 2 it seems that in general the activity of various carotenoid pigments after intravenous injection in dispersions is similar to that after oral administration. Carotenoids not containing the $\beta$-ionone ring showed, as might be expected, no vitamin A activity, although they were actively metabolized, as judged by their rapid disappearance, only a small fraction of the initial dose remaining in the blood and liver after $24 \mathrm{~h}$. As when it is given orally, $\beta$-carotene was about twice as well utilized as $\alpha$-carotene. These findings indicate a similarity in the mechanism of breakdown of carotenoids after oral and intravenous administration.

Bieri (1955), working with chickens, has also reported inefficient conversion into vitamin $\mathrm{A}$ of injected cryptoxanthin, as indicated by liver storage. He was, however, able to demonstrate by growth studies that some conversion did occur, and he concluded that the conversion is sufficient to permit normal growth but not sufficient to achieve liver storage of vitamin $\mathrm{A}$.

In the experiments reported here, retinene differed both from the other carotenoids and from the vitamin $A$ acetate dispersions used in our earlier work. It was more rapidly converted into vitamin $A$ than the other carotenoids, none remaining in the blood or liver after half an hour, and appeared to be somewhat more stable than vitamin A acetate similarly injected. Further, the initial increase in liver storage even at half an hour was in the ester form, whereas with all other substances the alcohol predominated. These observations are in keeping with those of Glover, Goodwin \& Morton (1948) on oral and parenteral administration.

Conflicting reports are still appearing about the possible effect of thyroid activity on the conversion into vitamin A of orally administered carotene, some workers claiming that conversion is impaired in hypothyroid and enhanced in hyperthyroid animals. Cama \& Goodwin (1949) have, however, suggested that these differences are associated with the effect of hypo- and hyperthyroidism on intestinal absorption rather than with any direct effect on the mechanism of conversion. Intravenously administered carotene dispersions offer a means of studying any direct effect of the thyroid 
without the complicating factor of intestinal absorption. It seems clear from the results obtained that under these conditions thyroid activity has no effect on the conversion. Higher liver vitamin A storage in animals rendered hypothyroid with thiouracil has also been reported by Bieri (1949) and would appear to be a direct effect of this substance rather than of hypothyroidism. This aspect is being further investigated, and the finding may help to explain some of the contradictory reports about the influence of thyroid function on the intestinal conversion of carotene into vitamin $\mathrm{A}$.

An interesting strain difference was apparent between the Wistar rats used in this investigation and the hooded Norwegians used previously by Kon et al. (1955). Whereas vitamin $A$ in the blood and liver after injection of carotene reached similar levels in both strains, in the present investigation the level of carotene in the liver at 2 and at $24 \mathrm{~h}$ was only about one-quarter of that obtained when Norwegian hooded rats were used. At the same time it is apparent from Table 3 that big differences were found in the amounts of carotene in the liver at $24 \mathrm{~h}$. We have no explanation for these differences unless they reflect variations in the physical state of the carotene dispersions.

As to the site of conversion, Bieri \& Pollard (1954) have shown that the course of conversion is not influenced by the removal of the intestine or the kidneys or by partial hepatectomy. However, it is well established that residual liver tissue, even though isolated by ligating the major blood vessels, is still to some extent functional. This view is confirmed by our experiments, in which the injection of carotene in Tween after the ligating and severing of the vena porta and hepatic artery resulted in the appearance of appreciable quantities of carotene in the liver. For this reason we carried out our experiments in the complete absence of the liver. It was found necessary to ligate the aorta first to reduce cyanosis of the intestine and to prolong the survival time of the rats. This ligation in fact virtually restricted the circulation to the anterior portion of the rat, but collateral circulation resulted in the appearance of a small amount of carotene in the blood drawn at slaughter from the posterior end of the animal.

Our experiments prove conclusively that conversion of injected carotene can take place in the complete absence of the liver and support our previous suggestion and that of Bieri \& Pollard (1954) that the extra-intestinal conversion may not be restricted to any one site but may occur in any tissue, as suggested for retinene by Glover $e t$ al. (1948).

\section{SUMMARY}

I. The metabolism of various carotenoids given intravenously as aqueous dispersions in Tween 40 (polyoxyethylenesorbitan monopalmitate) has been studied in rats.

2. Vitamin A alcohol increased markedly in blood and liver of vitamin A-deficient rats $2 \mathrm{~h}$ after the injection of as little as $25 \mu \mathrm{g}$ carotene in Tween. A similar dose produced no detectable increase in the blood of animals from the same batch that had received a large dose of vitamin $\mathrm{A}$, but $250 \mu \mathrm{g}$ resulted in a $50 \%$ increase in the vitamin A alcohol levels of their plasma. 
I34 W. A. McGillivray, S. Y. Thompson and N. A. Worker 1956

3. $\alpha$-Carotene was found to have half the activity of $\beta$-carotene similarly injected. Lycopene, zeaxanthin and xanthophylls were completely inactive. Cryptoxanthin, although active orally, showed little activity when injected. All carotenoids disappeared from the blood at similar rates and gave similar liver stores of pigment.

4. Retinene disappeared rapidly from the blood and was efficiently converted into vitamin $\mathrm{A}$ ester.

5. The metabolism of intravenously administered carotene was not influenced by changes in thyroid function.

6. Conversion of injected carotene into vitamin A can occur in the complete absence of the liver.

We are grateful to the Department of Scientific and Industrial Research for a grant towards this investigation. One of us (S.Y.T.) is indebted to the Royal Society, the Nuffield Foundation and the Board of The Dairy Research Institute (N.Z.) for a travelling fellowship, during the tenure of which the work reported here was carried out. The investigation also forms a section of a thesis submitted by one of us (N.A.W.) in partial fulfilment of the requirement for the degree of Ph.D. of the University of New Zealand. We also wish to thank Miss Fay Frecklington for help with much of the experimental work.

\section{REFERENCES}

Ball, S., Goodwin, T. W. \& Morton, R. A. (1948). Biochem. F. 42, 5 I6.

Bieri, J. G. (1949). Fed. Proc. 8, I 84.

Bieri, J. G. (1955). Arch. Biochem. Biophys. 56, 90.

Bieri, J. G. \& Pollard, C. J. (1954). Brit. F. Nutr. 8, 32.

Braude, R., Foot, A. S., Henry, K. M., Kon, S. K., Thompson, S. Y. \& Mead, T. H. (194r). Biochem. F. 35, 693.

Cama, H. R. \& Goodwin, T. W. (1949). Biochem. F. 45, 236.

Church, D. C., MacVicar, R., Bieri, J. G., Baker, F. H. \& Pope, L. S. (1954). F. Anim. Sci. 13, 677. Glover, J., Goodwin, T. W. \& Morton, R. A. (1948). Biochem. F. 43, rog.

Kon, S. K., McGillivray, W. A. \& Thompson, S. Y. (1955). Brit. F. Nutr. 9, 244.

Morrison, P. R. (1947). F. biol. Chem. 169, 667.

Thompson, S. Y., Ganguly, J. \& Kon, S. K. (1949). Brit. F. Nutr. 3, 50. 